\title{
eDucAçÃo MAteMátiCA AefeTIvA: nomes e movimentos em avessos*
}

\author{
AefFecTIvE MAthEmAtiCS eDucAtIOn: \\ names and moviments in inside outs
}

\author{
Sônia Maria Clareto** \\ Roger Miarka ${ }^{* * *}$
}

\begin{abstract}
Resumo
Como perguntar por pesquisas e práticas efetivas em educação matemática? Como perguntar pela efetividade da educação matemática? Atravessado por inquietações que brotam do embate com estas questões, o presente artigo se lança em desafio: pensar a educação matemática em um duplo: área e movimento. Educação Matemática se comportando como uma área do conhecimento e educação matemática se lançando como movimento. $\mathrm{O}$ que acontece no entre desse duplo? Polêmica. Uma guerra insólita e intempestiva, um combate que costura área e movimento, em direito e avesso e avesso e direito e movimento e área e área e movimento e... Avesso e direito em costura. Um duplo. Um movimento que se territorializa. Um território que clama por movimento. Uma polêmica costura, tece e enreda direito e avesso em uma única trama. Uma polêmica com a Matemática entendida como área, mas também com a matemática como movimento. Uma disputa, mais que isso, uma polêmica à moda grega: polemikós, a arte da guerra. Multiplicidade. Quanto de adjetivação comporta uma matemática? Quanto suporta uma matemática ao ser adjetivo e não substantivo? Este escrito explora três cenários: um deles opera com a Educação Matemática como área de conhecimento, abordando a constituição da área e seus processos de institucionalização; o outro pensa o movimento da educação matemática; um terceiro costura os cenários anteriores em enredamentos: área e movimento e educação matemática e Educação Matemática e nome próprio e nome comum e e e...
\end{abstract}

Palavras-chave: Polêmica. Área e Território. Movimento.

Outras palavras-chave: Multiplicidade. Efeito. Afeto. Efetivo. Afetivo. Guerreiros da Verdade. Amantes da Insólita Batalha.

\begin{abstract}
How to ask about effective research and practices in mathematics education? How to ask about the effectiveness of mathematics education? Crossed by concerns that arise from the struggle with these issues, this article launches itself in defiance: to think of mathematics education as a double: area and movement. Mathematics Education behaving as an area of knowledge and mathematics education behaving as a launching movement.

\footnotetext{
* Desformatado de acordo com as normas da ABNT, em nome de uma política de narratividade que permeia o próprio artigo e destaca a polêmica como condição existencial, tanto para os processos de criação e manutenção de uma área, como para os movimentos criadores e criativos que a colocam em marcha.

** Professora do Departamento de Educação da Universidade Federal de Juiz de Fora. Doutora em Educação Matemática pela Universidade Estadual Paulista, campus de Rio Claro. E-mail: sclareto@yahoo.com.br

**** Professor do Departamento de Educação Matemática da Universidade Estadual Paulista. Doutor em Educação Matemática pela Universidade Estadual Paulista, campus de Rio Claro. E-mail: romiarka@gmail.com
} 
What happens in between this double? Controversy. An unusual and untimely war, a fight that sews area and movement on one side, inside out, front and back, and movement and area and area and movement... On one side and inside out. A double. A movement that becomes territory. An area that cries out for movement. A controversial sewing, weaving one side and its inside out in a single plot. A controversy with mathematics understood as area, but also with mathematics understood as movement. A dispute, more than that, a controversy in the Greek way: polemikós, the art of war. Multiplicity. How many adjectives does math bear? How much can math tolerate being an adjective and not a noun? This writing explores three scenarios: one operates with mathematics education as a field of knowledge, addressing the creation of this area and its institutionalization processes; the other thinks over the movement of mathematics education; a third sews the previous scenarios weaving them: area and movement and mathematics education and Mathematics Education and first name and common name, and so forth...

Keywords: Controversy. Area and Territory. Movement.

Other keywords: Multiplicity. Effect. Affection. Effectiveness. Affectiveness. Warriors of Truth. Lovers of the Unusual Battle.

\section{eDucAçÃo MAteMátiCA}

Perguntar(-se).

Perguntar, verbo intransitivo. Evocando o verbo perguntar, vem à tona sua bitransitividade: o verbo perguntar é transitivo direto e indireto. Pergunta-se algo a alguém. Mas, se se pergunta algo a alguém, há o desejo de uma resposta, dada por este alguém. Aqui, perguntar é tomado como intransitivo: pergunta-se, sem desejo de resposta. Pergunta lançada: problematização.

Como ${ }^{l}$ perguntar por pesquisas e práticas efetivas em educação matemática? Como perguntar pela efetividade de pesquisas e práticas em educação matemática? Como perguntar pela efetividade em educação matemática?

Educação matemática: área do conhecimento? comunidade científica? movimento profissional?

Educação Matemática e educação matemática e Educação matemática e educação Matemática e... e... Um nome? Dois nomes? Quatro nomes? Muitos nomes? Infinitos! Uma nomenclatura? Um movimento? Um território? Uma instituição?

O que a nomeação de um movimento, entidade ou instituição produz?

\section{Pequeno Tratado dos Nomes}

\footnotetext{
${ }^{1}$ A pergunta "como" tem caráter modal - problematizam-se os modos de se perguntar por pesquisas e práticas efetivas em educação matemática - e não metodológico - quer dizer, não se pergunta por caminhos percorridos ou a percorrer, nem por procedimentos para se chegar ou se atingir a efetivação de pesquisas e práticas em educação matemática.
} 


\section{Nomear.}

Nomear: verbo intransitivo. Nomeadamente, o verbo nomear é transitivo direto, mais ainda, verbo transobjetivo. $\mathrm{O}$ verbo nomear pede objeto e esse objeto pede complemento. Nomear sem objeto, sem sujeito, sem complementaridade. Simplesmente, nomear. Intransitivo.

Nomear: dar um nome. Nome: vocábulo ou locução que tem a função de designar uma pessoa, um animal, uma coisa ou um grupo de pessoas, animais e coisas. Dentre os nomes que designam, há os nomes comuns e os nomes próprios. Comum, do latim communis. Uma acepção: "Do uso ou domínio de todos os de um lugar ou de uma coletividade". Próprio, do latim proprius. Uma acepção: "Que pertence exclusivamente a alguém”.

Próprio, propriedade, proprietário, possuidor. Quem possui quem? O nome possui o objeto ou sujeito, ou é o sujeito ou objeto que possui o nome? Nome, nomear, criar propriedade, criar território, possuir. Nomes comuns e nomes próprios... Nomes propriedades e nomes em geral, sem proprietário. O que afirmam um nome comum e um nome próprio?

A teoria dos nomes próprios não deve ser concebida em termos de representação, porque remete à classe dos "efeitos": estes não são uma simples dependência das causas, mas o preenchimento de um domínio, a efetuação de um sistema de signos. (DELEUZE; GUATTARI, 2014a, p.120)

Nomes comuns são de uso coletivo. Atravessam, cortam o mundo. Indicam, agrupam, identificam. No entanto, essa identificação não ocorre projetivamente. Um animal não se torna cavalo porque foi assim nomeado. O cavalo é o que é. O nome comum cavalo é posterior à sua existência. Atravessa o animal dizendo algo, sem pretensão de dizer mais que isso. Por ser comum, aceita o movimento. Nomes comuns aparecem e desaparecem, mudam de acepção na língua, ganham ou perdem força no vocabulário do qual fazem parte. Nomes comuns se movimentam no seio de onde foram criados. Mas também, no seu avesso, o nome comum identifica: cavalo identificado por sua "cavalidade". Nome comum tem avesso e, nesse avesso, forças buscam por identificação, por apropriação, por propriedade, por nome próprio.

O nome próprio marca, demarca, institui. Traz limites para dizer o que se é, domestica. Sou Roger, sou Sônia. Roger e Sônia demarcam uma extensão de um território identitário. Nomes-territórios. Mas são apenas Roger e Sônia? Como Roger e Sônia mantêm seus corpos e seus movimentos e como são aprisionados? "Não, Roger não faria isso”, "Isso é próprio da Sônia”, "Esses não são a Sônia e o Roger que conheço”.

Assim, quando não existe unidade da coisa, há pelo menos unidade e identidade da palavra. Pode-se observar que as palavras são tomadas aqui num uso extensivo, quer 
dizer, funcionam como nomes comuns que asseguram a unificação de um conjunto que elas subsumem. O nome próprio só vem a ser um caso extremo de nome comum, compreendendo nele mesmo sua multiplicidade já domesticada e relacionando-a a um ser ou objeto posto como único. O que é comprometido, tanto do lado das palavras quanto das coisas, é a relação do nome próprio como intensidade com a multiplicidade que ele apreende instantaneamente. (DELEUZE; GUATTARI, 2014a, p. 53).

Como ir aquém e além de nossos nomes? Como ir além e aquém desses domínios próprios? Como, a partir de nossos nomes, tão bem territorializados, desterritorializamo-nos? Como podemos deixar de ser, ainda que tenhamos nomes próprios? Aliás, de onde vêm nossos nomes próprios?

Nascemos agressivamente. Com um tapa brutal em nossas costas, choramos. O chorar indica que respiramos, que deixamos o ventre da mãe e ganhamos o mundo. Nascemos em um movimento, em um grito que ganha o mundo. Junto a esse movimento de descoberta ganhamos um nome próprio, que pouco identifica. Um bebê é todo possibilidades, um indefinível. O nome de um bebê é tão somente um nome, um nome comum, um vir a ser nome próprio. Enquanto comum, é pura vontade de poder, movimento afirmando vida... mas já um nome que intenta a marcação de um território, cuja filiação visa à propriedade. Em seu nascimento, bebês escapam à filiação e aos nomes próprios? São corpos que desejam. Choram para o mundo e pelo mundo. Berram. Nomes comuns que berram, nomes-movimento em um vir a ser nome-próprio.

Nomes próprios possuem filiação. Bebês gerados têm seus nomes escolhidos. Mais que isso, escolhidos como e por nomes-território. O que significa escolher um nome? Escolhe-se um nome dentre aqueles já presentes em um território social. Nomes próprios são compostos por sílabas, iniciam-se com letra maiúscula, têm sonoridade. Um "abcdef" não é um nome próprio, "aveRIm" tampouco. Nomes próprios nascem em uma tentativa de territorializar o bebê desterritorializado, recém desprendido do calor e do conforto da barriga da mãe. São nomes-movimento que, ironicamente, nascem de nomes-território e tendem a nomes-territórios.

\section{educação matemática : nome comum : nome-movimento}

Lançar(-se). 
Lançar, verbo intransitivo. Lançar, em sua bitransitividade: quem lança, lança algo a alguém: verbo transitivo direto e indireto. Aqui, intransitivamente: lançar, lançar-se, sem alvo. Fazendo-se em lançamentos.

Lançar-se em problematização: educação matemática sem um nascedouro, sem uma origem, sem um ponto inicial. Educação matemática começando pelo meio: desde que a matemática é inventada, é produzida, há educação matemática. Um movimento junto à matemática, mas também belicoso em relação a ela: atritando, produzindo(-se) em faíscas. Outros movimentos junto à educação, à história, à filosofia, à didática, à universidade, à escola, à sociedade, a José, a Maria, à vida...

A Educação Matemática é mais ou menos isso. É um amálgama. Eu não diria que é uma mistura, porque na mistura as coisas são heterogêneas e podem ser separadas; mas suponho que no amálgama acontece alguma coisa química que não possa ser desfeita. (VIANNA, 2000, p. 519) ${ }^{2}$

Surge uma educação matemática. Uma educação matemática lançada.

A Educação Matemática só é possível porque, uma vez que existe a matemática, as pessoas necessitam trocar experiências matemáticas entre si. [...] Mas não basta apenas que exista a matemática, ela deve ser instituída como uma prática social relevante e é essa relevância e esse modo de instituição que vão determinar a necessidade de uma [E] educação [M]matemática.

[...] ela [a [E]educação [M]matemática] não existe porque a matemática é difícil, porque é abstrata, porque é egocêntrica ou porque é bela..

A [E]educação [M]matemática depende, de modo radical, de como a sociedade instituí, a cada época, a matemática como prática social relevante. A [E]educação [M]matemática existe porque existindo a matemática, as sociedades ao fazerem dela um dos elementos de sua cultura, criaram necessidades específicas de comunicação e, a par destas necessidades, encontram dificuldades no exercício desta comunicação. É em função destas necessidades e dificuldades que se constituiu uma educação [M]matemática. (VIANNA, 2003, p. 48, grifo do autor)

Educação matemática um dia nasceu como nome - Educação Matemática -, trazendo consigo marcas de filiação de duas mães que se veem em seu rebento e se projetam por meio de seus nomes: Educação e Matemática. Nasce de duas mães divorciadas, em um movimento que desterritorializa as tentativas de territorialização de seu próprio nome. Não basta chamar o bebê com o nome das mães. O filho é o poder de criação no entre-espaço de uma mãe e de outra. Em seu ato de nascimento, a Educação Matemática é apartada de cada uma das mães ao deixar seus ventres. Rebento que arrebenta. Não é Matemática, não é Educação, ao mesmo

\footnotetext{
${ }^{2}$ Esta pesquisa de doutoramento de Carlos Roberto Vianna reúne histórias de vida de quinze professores de departamentos e institutos de Matemática de universidades brasileiras, que, atuando nesses espaços, ao longo de sua carreira optaram por exercer sua prática no campo da Educação Matemática. É importante destacar que os trechos utilizados neste artigo com referência em Vianna (2000) são excertos de entrevistas com esses professores.
} 
tempo em que atravessa uma, outra e ambas. É multiplicidade de atravessamentos. É multiplicidade em atravessamentos.

O Oscar me procurou, há poucos dias, pois está havendo um problema com o regime de trabalho dele. Estão dizendo que ele não tem maturidade matemática para ser um RDI-DP ${ }^{3}$ em matemática, pois ele não produz... O que ele produz é na área de educação, e não em matemática. [...] Da parte da Educação há o estereótipo de que o matemático é o bitolado, é o que não tem abertura mínima para coisa nenhuma, e só sabe falar de números. (VIANNA, 2000, p. 532, nota nossa)

Um nome é lançado em movimento: educação matemática. Um nome composto. Um nome próprio? Educação adjetivada de matemática? A E[e]ducação ganha um adjetivo e a M[m]atemática perde seu efeito substantivo? Quanto de adjetivação comporta uma matemática? Quanto suporta uma matemática ser adjetivo e não substantivo?

Saindo do ovo, buscou incessantemente questionar os caminhos pelos quais a Matemática se fez hegemônica: dentre todas as formas do conhecimento com as quais tinha interlocução, era a Matemática imperiosa e onipotente a que mais queria subverter, aquela de cujos valores mais queria se afastar. Por isso, a Educação Matemática tinha afinidades com outras Matemáticas, consideradas por algumas formas do conhecimento como menos importantes. (FERNANDES, 2014, p.165).

\section{Educação Matemática : Nome Próprio : Nome-Território}

\section{Apropriar(-se).}

Apropriar, verbo intransitivo. Apropriadamente, o verbo apropriar é considerado bitransitivo apropriar algo a alguém, adequar - e transitivo direto - apropriar-se de algo, tornar próprio. Intransitivamente: apropriar, apropriar-se. Fazer(-se) próprio.

Um desejo se faz: institucionalização da Educação Matemática como área de pesquisa, através da criação de uma sociedade científico-acadêmica que congregasse professores, pesquisadores. Um movimento que nasce de alguns professores e pesquisadores e que se lança como desafio a uma área. Um movimento é lançado em uma área... desterritorialização?

Nós, abaixo-assinados, brasileiros reunidos na 6a. Conferência Interamericana de Educação Matemática, em Guadalajara, Jalisco, México, de 23 a 27 de novembro de 1985, considerando: que o número de brasileiros aqui reunidos e a diversidade de cidades representadas demonstram a existência de uma quantidade significativa de pessoas de diferentes formações acadêmicas ocupadas com a Educação Matemática no Brasil - que uma parte importante dos trabalhos aqui apresentados constituem uma contribuição da comunidade científica e educacional brasileira para a 6a. CIAEM; - que muitos dos brasileiros aqui reunidos encontram-se pela primeira vez para uma discussão e análise conjunta de suas idéias, nos dirigimos aos colegas brasileiros que se ocupam de Educação Matemática para propor a criação da Sociedade Brasileira de Educação Matemática, com o objetivo de

\footnotetext{
${ }^{3}$ Regime de Dedicação Integral à Docência e à Pesquisa.
} 
estimular e coordenar o intercâmbio de estudos e atividades realizadas no Brasil na área de Educação Matemática.

Motiva-nos a força da experiência aqui vivida caracterizada pela oportunidade de conhecer e refletir sobre muitos trabalhos científicos que se reforçam e se completam no confronto e na discussão.

A efetiva organização da Sociedade Brasileira sobre Educação Matemática poderá se fazer no Encontro Nacional que sugerimos para os dias 8, 9 e 10 de agosto de 1986 em local a ser determinado. (PEREIRA, 2005, p. 20-21, grifos do autor) ${ }^{4}$.

Um movimento dentro do movimento que movimenta uma área. Desterritorializa um território, em disputas. Muitos movimentos engendrando um Movimento Pró-SBEM, desde a formação de uma comissão para a elaboração do estatuto da Sociedade, na plenária final do I ENEM, na PUC de São Paulo/SP, até a criação da SBEM e a homologação do seu estatuto, na plenária do II ENEM, em Maringá/PR, em janeiro de 1988. A ideia era congregar “profissionais que atuassem com Educação Matemática, compreendida em seus mais amplos aspectos interdisciplinares, didáticos, pedagógicos, sociológicos, filosóficos, históricos, sociais" (PEREIRA, 2005, p. 101).

Movimento Pró-SBEM: movimento no plural. Um plural que singulariza as disputas e coloca em funcionamento uma maquinaria: a produção da institucionalização de um movimento que culmina na efetivação da institucionalização de uma área do conhecimento.

Em várias reuniões o grupo dos 11 signatários, modificado pela deserção de alguns e pela adesão de outros, verificou que a tarefa não seria fácil. Pressões diretas $e$ indiretas questionavam a criação da nova sociedade ("Por que mais uma?") $e$ mesmo desacreditavam que a idéia de um congresso nacional era factível ("Ainda não há massa crítica de pesquisa que possa alimentar um congresso do gênero"; "Não há capacidade organizacional"). (D'AMBROSIO apud PEREIRA, 2005, p. 82 , grifos do autor). ${ }^{5}$

No movimento Pró-SBEM houve a defesa de que a finalidade da Sociedade deveria ser a promoção do desenvolvimento da Educação Matemática como área do conhecimento. O termo área do conhecimento foi motivo de disputa e problematização. Quem defendia ${ }^{6}$ a colocação desta expressão mais técnica o fazia por

\footnotetext{
${ }^{4}$ Denizalde Pereira realizou uma pesquisa acerca da constituição da Sociedade Brasileira de Educação Matemática que culminou na produção de sua tese de doutoramento na Unicamp. Nesta tese ele investiga os modos como a SBEM foi sendo construída, estudando o Movimento Pró-SBEM, disparado no I Encontro Nacional de Educação Matemática I ENEM, em 1987, que foi acionado a partir desta carta, assinada por, pelo menos, Antônio José Lopes Bigode, Esther Pillar Grossi, Anna Franchi, Vânia Maria Pereira dos Santos, Ubiratan D'Ambrosio, Terezinha Nunes Carraher, Lucília Bechara Sanchez. Há mais algumas assinaturas que não puderam ser identificadas, num primeiro momento.

${ }^{5}$ Relato de Ubiratan D'Ambrosio presente nos Anais do I Encontro Nacional de Educação Matemática, em 1988, acerca do movimento que deu início ao processo de criação da SBEM.

${ }^{6}$ Denizalde Pereira argumenta que Roberto Ribeiro Baldino, secretário da Comissão Central do Movimento PróSBEM, foi defensor desta proposição.
} 
[...] considerá-la como consagrada por órgãos governamentais (CNPq, CAPES) para abranger Ciências Exatas, Humanas e Sociais. Nas tabelas desses órgãos, em relação às áreas e sub-áreas, já figurava "Matemática" e "Educação", mas não "Educação Matemática". Essa era uma proposição militante para inserir a Educação Matemática no contexto efetivo da existência das ciências no plano nacional (PEREIRA, 2005, p. 181).

Entre confrontos internos e externos, um movimento vai se dando em meio a um quadro de disputa com a já consolidada Sociedade Brasileira de Matemática - SBM e diferenças entre grupos que se colocam dentro do próprio movimento.

[...] Constitui-se um grupo de trabalho, para a formação da SBEM, que acabou se dividindo: uma parte defendia tenazmente a presença de professores de primeiro e segundo graus na formação da Sociedade Brasileira de Educação Matemática, sendo o Baldino um dos "cabeças" deste grupo, com a nossa participação; e uma outra parte que tentava formar uma Sociedade elitista, tentava formar um grupo de doutores que decidisse como as coisas iriam funcionar. Mas, se existisse um só grupo, o processo democrático não teria se desenrolado.

[...] Na verdade a Sociedade acabou saindo a meio-termo entre um ponto e outro, entendeu? (PEREIRA, 2005, p. 81, grifos do autor) ${ }^{7}$.

Movimento que demarca um tempo, uma história, um território...

[...] parecia que a Educação Matemática queria mais: que seu dentro e fora fossem institucionalizados, que as cercanias de suas fronteiras fossem melhor definidas, que as afirmações que cerceiam e definem suas distâncias das outras formas do conhecimento fossem melhor fundamentadas. (FERNANDES, 2014, p.163).

Um território, com seus muros e sua estrutura, protege seus habitantes, mas também institui um dentro e um fora, com a instituição de um conjunto de regulações que mantêm fronteiras mais ou menos definidas, com o desejo de diferenciá-lo [por meio de uma suposta cerca dentro-fora]

[...] das demais formas do conhecimento quanto quer que, sendo ela uma forma do conhecimento que está sendo criada, haja uma diferenciação entre o que vale e o que não vale, entre quem está e quem não está, entre aquele que/o que pode e aquele que/o que não pode. (FERNANDES, 2014, p.164).

\section{e}

Educação Matemática: acitámetam oãçacude

e

entre uma área e um movimento

e

\section{multiplicidade de um entre área-movimento}

\footnotetext{
${ }^{7}$ Afirmação de Ledo Vaccario Machado, em entrevista a Denizalde Pereira, acerca do movimento que deu início ao processo de criação da SBEM.
} 
alinhavo do avesso do avesso do avesso do avesso do...

e

costura do direito com o avesso com o direito com o avesso com...

$\mathbf{e}$

Costurar.

Costurar, verbo intransitivo. Transita entre uma face e outra, no avesso e no direito, no avesso e na forma. Costurar, alinhavar, prender e soltar: verbos-ação em composição.

Costura: um movimento solicita saída do território, desterritorialização. Um movimento se dá por aliança, uma área se constitui por filiação. Então, como compor?

Como um movimento - educação matemática - constitui-se em uma área? Como uma área - a Educação Matemática - mantém-se como movimento?

Eu vejo essa expressão, Educação Matemática, com pelo menos dois significados. O primeiro se refere ao movimento de Educação Matemática. A palavra importante é movimento, porque é como o movimento dos sem-terra, movimento das mães da praça de maio; é um movimento porque veio da sociedade civil, veio dos professores de matemática; é movimento porque tem um nível de organização bastante razoável; embora esteja engatinhando aqui no Brasil, ele é internacional; é um movimento onde há muita troca de informação, existem publicações. E é um movimento ímpar dentro da educação, porque em outras áreas eu não vejo coisa semelhante. (VIANNA, 2000, p. 523)

O movimento da educação matemática foi ganhando tônus em polêmica com uma área de conhecimento, aceita e reconhecida, institucionalizada e instituída, a Matemática. Polêmica aqui não como controvérsia, mas, como em sua origem grega, como arte da guerra, polemikós. Arte como aquela do artesão que, com suas mãos, expressa e com a matéria, pratica. Arte do artesão enamorado da prática. Arte do guerreiro que guerreia por amor à guerra, movido pela possibilidade de mover-se em meio à guerra e territórios outros. Nesta arte trata-se de praticar a guerra, encontrando-se em situação de risco efetivo de ganhar ou perder.

Essa Educação Matemática, apesar de se encrencar com aquela Matemática hegemônica e mantê-la banida no fora, também reconhece a importância de um viajar junto a ela, permitindo, assim, o dentro - há algo que as conecta. Sua constituição não estava apenas marcada na repulsa a uma Matemática imperiosa, mas numa aproximação quase amorosa que fez com que fossem questionados, em um dado momento, seus usos nos jogos de verdade e poder. (FERNANDES, 2014, p.168). 
Não se trata de alcançar as condições pelas quais um vencedor se arrogaria ser o único ou o melhor de todos: "Para os antigos gregos, diante dos arroubos e dos gritos entusiasmados dos vencedores, estavam os deuses em prontidão para exigir que o sentimento arrogante da eterna vitória não fizesse sucumbir o nobre desejo do combate eterno" (LEITE, 2014, s/p) . Não se trata, pois, de entrar em combate por uma verdade, ou em nome de uma verdade. Na polêmica, o combate não se dá entre guerreiros $d a$ verdade, mas entre "amantes do insólito da batalha, que, quando boa, exige certo tempo e lugar, um apreciável inimigo e um conjunto belicoso de armas de combate".

Em polêmica com uma área, um movimento vai se dando: em um certo tempo e lugar; em combate a um apreciável inimigo; lançando mão de um conjunto belicoso de armas. Uma batalha, um combate, uma polêmica.

Uma relação belicosa de forças. Uma vontade de poder: toda força quer se impor, toda força se destina ao mando. Um movimento, quando na belicosa batalha, no entre das relações de forças, na potência afirmativa da polêmica, quer o mando. Vontade poder afirmativa: uma força quer se impor e é toda movimento ${ }^{9}$.

Mas e se os deuses não estiverem lá de prontidão, na batalha, para exigir que o desejo do combate eterno não se renda ao sentimento de vitória, à seguridade da vitória? E se os deuses tiverem abandonado o campo de batalha ou tiverem sido expulsos de lá? Resta só a arrogância da eterna vitória e o medo de perder o território conquistado. A polêmica, e a belicosidade da batalha sucumbem ao medo e ao desejo de manutenção do território, da conquista? Resta a manutenção e as forças reativas no comando, vontade de poder negativa: “é que olhei demais para dentro de mim! é que olhei demais para dentro de..." (LISPECTOR, 1964, p. 87).

Um território conquistado demanda manutenção. Guerreiros $d a$ verdade institucionalizam, criam e reforçam estrias e caminhos de seu território. Expandem-no, construindo muros ao seu redor. Em seu interior, caminhos, estrias a serem percorridos, a serem novamente trilhados.

\footnotetext{
${ }^{8}$ Este trecho foi retirado do texto para o exame de qualificação de doutorado de Marcos Vinícius Leite. O doutorando propõe uma escrita polêmica, que abdica da procura pela verdade, por um porto seguro ou por um conjunto de certezas. Escrita como movimento belicoso, no qual a disputa se dá não pelo estabelecimento de um território, mas pelo movimento incessante dos fluxos do pensar. A escrita que aqui se intenta é afetada pelo mesmo movimento.

${ }^{9}$ Esta discussão se constitui em diálogo com a chamada doutrina das forças ou doutrina da vontade de poder em Nietzsche (cf. Deleuze, 2001).
} 
$\mathrm{Na}$ manutenção, a tentativa de segurança na ocupação do território conquistado. Mecanismos de controle e dispositivos de efetivação de processos são produzidos. Segurança e seguridade se confrontam com o movimento do movimento. Um pouco de ordem, um pouco de domínio, um tanto de controle e umas doses de disciplinarização. O movimento se constitui em área, tornando-se disciplina.

\section{ATA DA ASSEMBLÉIA DE FUNDAÇÃO DA SOCIEDADE BRASILEIRA DE EDUCAÇÃO MATEMÁTICA (SBEM).}

Aos 27 (vinte e sete) dias do mês de janeiro de 1988 (hum mil novecentos e oitenta e oito), no auditório Dona Guilhermina, sito à Avenida Tiradentes, 740 (setecentos e quarenta), em Maringá, Estado do Paraná, com início às 16 (dezesseis) horas, realizou-se a Assembléia Geral de Fundação da Sociedade Brasileira de Educação Matemática (SBEM), contando com aproximadamente 600 (seiscentas) pessoas presentes. A mesa foi composta pelos seguintes elementos: Maria Laura M. Leite Lopes, Sérgio Roberto Nobre, Lucília Bechara Sanchez, Manuel Claudemir Silva Caldas e Emerson Arnaut de Toledo. A presidência da mesa esteve com Maria Laura M. Leite Lopes, que abriu os trabalhos e apresentou, em seguida, os membros da Comissão Central responsáveis pela organização da presente Assembléia: Lucília Bechara Sanchez, José Aluisio Ferreira Lima, Tânia Maria Mendonça Campos, Tânia S. Bascos, Elisete de Miranda, Jonas Martins Silva, Manoel Oriosvaldo de Moura, Luís Carlos Pais, José Luiz Magalhães de Freitas, Tadeu Oliver Gonçalves, Luiz Márcio Imenes, Roberto Ribeiro Baldino, Tânia Cristina B. Cabral, Janete Bolete Frant, Neri Terezinha Both Carvalho, Antônio Pinheiro de Araújo, Dione Lucchesi de Carvalho, Gelsa Knijnik, Lourdes Onuchic, Adelaide Reis Mendonça Salvador, Dora Soraia Kindel, Vanildo de Jesus Xavier, Maria Tereza C. Soares, Manuel Claudemir Silva Caldas, Sérgio Roberto Nobre, Eudes Barroso Júnior, Dario Fiorentini, Rômulo Campos Lins, Rômulo Marinho do Rego, Nilza Eigenheer Bertoni, Charles Guimarães Filho, Vânia Maria Pereira dos Santos, Ledo Vaccaro Machado, Marlene de Araújo, Regina Maria Pavanello, Maria Laura Lopes, Rafael Mousinho Gendi, Cristiano Alberto Muniz.

[...] A presidente da mesa informou a seguir, que a Comissão Central se reuniu no dia 26 (vinte e seis) de janeiro próximo passado para discutir as propostas de mudanças no estatuto, apresentadas após à Assembléia de discussão do mesmo realizada no dia 25 (vinte e cinco) de janeiro próximo passado e encaminhadas por escrito à Comissão Central até às 12 (doze) horas do dia 26 (vinte e seis) conforme encaminhamento aprovado na referida Assembléia. Informou também a presidente da mesa que a Comissão Central, nessa reunião, decidiu que só se fariam mudanças que garantissem a manutenção dos princípios que nortearam a elaboração do estatuto: que fosse sucinto e não regimental, que não entrasse em questões circunstanciais, que garantisse uma estrutura de sociedade aberta. Informou também que a Comissão Central nesta mesma reunião elegeu uma Comissão de sete membros para estudar a possibilidade de incorporar as mudanças propostas; [...].

[...] O Professor Antônio José Lopes interferiu, convocando os presentes a se organizarem em seus estados para real efetivação da tarefa da Diretoria Provisória: a de consolidação das bases da SBEM e condução do processo eleitoral.

[...] Eu, Lucília Bechara Sanchez, como secretária "ad hoc" lavrei a presente ata que depois de lida e aprovada será assinada por mim e pelo presidente da Assembléia. (PEREIRA, 2005, p. 151-152, grifos nossos). 
Que caminhos uma educação matemática produz? Entre a manutenção de um território e os movimentos de desterritorialização, que possibilidades são construídas? Uma educação matemática guerreira nômade: alisa, liga-se ao território de uma Educação Matemática, alisando-o $^{10}$. Na polêmica entre o alisar e o estriar que o movimento resiste: eDucAçÃo MAteMátiCA

Um movimento não cessa por completo, algo de movimento sempre escapa aos processos de disciplinarização e de controle. Algo sempre escapa. Brota por toda parte, aproveitando e aproveitando-se dos espaços não estriados. À moda da erva daninha, brota sem permanecer. Alastra-se vigorosamente. Uma educação matemática turbilhonar. Arrasa estrias, arrebenta como todo rebento. Arrebenta ventre de mãe, arrebenta espaços de uma E[e]ducação $M[m]$ atemática, possibilitando educações matemáticas outras: eDucAçÃo MAteMátiCA.

Uma educação matemática de nome comum. Uma Educação Matemática nome próprio. Uma educação matemática que estria o liso e alisa o estriado. Uma educação matemática que conquista um nome. Uma educação matemática que dribla a disciplinarização. Uma educação matemática que dribla a metodologização da pesquisa. Enrola a consistência e dá um nó na coerência, arrasa com qualquer dicotomia, resvala entre os dedos. Escapa!

[...] os espaços que permitem as formas dicotômicas também dobram-se sobre si mesmos, constituindo espaços outros que colocam em cena não as fronteiras desenhadas por linhas contínuas, mas fronteiras sutis, móveis, líquidas. Essa operação, em que a própria dicotomia questiona a si mesma, torna dentro e fora imbricados, indissociáveis e inteiramente comunicáveis, como que separados apenas por uma linha muito tênue e porosa. O caminhar nesse espaço é um perceber-se em um provisório das relações, não relações estabelecidas com o espaço, mas apenas relações que se confundem com aquelas que constituem a si mesmo. Nesse espaço, dentro e fora confundem-se na medida em que operam em idas e vindas, mas sempre junto às passagens: um espaço-meio, não um espaço que é meio; um espaço-relação, mas não um espaço em que a relação acontece e que dela deriva. (FERNANDES, 2014, p.165-166).

Perguntar(-se). Nomear(-se). Lançar(-se). Apropriar(-se). Costurar(-se).

Verbos-ação que movimentam uma educação matemática: eDucAçÃo MAteMátiCA. Que movimentam uma escrita. Que movimentam uma composição. Que movimentam um viver junto a uma eDucAçÃo MAteMátiCA.

Mas também: Territorializar(-se). Desterritorializar(-se). Compor(-se). Polemizar(-se).

\footnotetext{
${ }^{10}$ Aqui operamos com os conceitos "liso" e "estriado" de Deleuze e Guattari (2014b).
} 
Como perguntar por pesquisas e práticas efetivas em Educação Matemática? Como perguntar por pesquisas e práticas efetivas em uma área do conhecimento? Como perguntar pela efetividade de pesquisas e práticas em uma área do conhecimento? Como perguntar pela efetividade de uma área do conhecimento?

\title{
Efetivar.
}

Efetivar: verbo transitivo direto. Produzir efetivação, tornar efetivo. Ser efetivo. Tornar estável. Consolidar.

Perguntar pela efetividade talvez traga a marca da ação que busca pela qualidade daquilo que atinge seu objetivo. O movimento da educação matemática atingiu seus objetivos? Sim, não, talvez. A Educação Matemática como área do conhecimento atingiu seus objetivos? Sim, não, talvez. Muitos movimentos ainda movimentam a área, compondo e decompondo objetivos, metas, propósitos...

Como perguntar por pesquisas e práticas efetivas em Educação Matemática?

Efetivo, efetividade, efeito, efetuação, afeito, afeição, afeto, afetividade, afetar, afetação, afecto. Como rimar essas palavras? Como rimar efetivo com afetivo?

$\mathrm{E}[\mathrm{e}]$ ducação $\mathrm{M}[\mathrm{m}]$ atemática efetiva ou $\mathrm{E}[\mathrm{e}]$ ducação $\mathrm{M}[\mathrm{m}]$ atemática afetiva?

Produzir efeitos ou produzir afetos? Causa de efeitos ou por si só um efeito sem causa? Efeito que afeta? E[e]ducação M[m]atemática aefetiva? eDucAçÃo MAteMátiCA AefeTIvA?!

\begin{abstract}
A ideia de afeto em Deleuze vem de Espinosa, que propunha a afeição (latim affectio) e o afeto (affectus), sendo que esta é a representação do nada, isto é, uma forma de pensamento vinculado ao nada, algo não representativo. Deleuze exemplifica isso com o verbo 'querer', o que queremos sobrecai em alguma coisa, entretanto, o fato isolado de querer não se coloca como ideia, mas, sim, como afeto. Sendo assim, o afeto implica em uma ideia, contudo, são modos diferentes de pensamento. (LIMA; ALVARENGA, 2012, p.33).
\end{abstract}

\section{eDucAçÃo MAteMátiCA AefeTIvA?!}

Um território. Uma área. Um movimento... Vidas. Uma educação matemática, uma vida. Vidas que habitam um território, vidas que movimentam e se movimentam. Talvez perguntar pela efetividade da área seja perguntar pelo movimento de produção de vida. Perguntar: que tipo de vida esta área afirma? Que tipo de vida uma educação matemática 
afirma? Um perguntar ético. Uma educação matemática: a produção de uma ética? A produção de uma vida, uma existência, uma estética.

Que afetos uma educação matemática produz? Que efeitos ocorrem na produção de uma educação matemática?

Produção e afirmação e movimentação e invenção: áreas e movimentos e vidas...

Lucília e Josés e Tânia e Tânia e Elisete e Jonas e Manoel e Luís e Tadeu e Luiz e Roberto e Tânia e Janete e Neri e Antônio e Dione e Gelsa e Lourdes e Adelaide e Dora e Vanildo e Maria Tereza e Manuel e Sérgio e Eudes e Dario e Rômulo e Rômulo e Nilza e Charles e Vânia e Ledo e Marlene e Regina e Maria Laura e Rafael e Cristiano. Outras lucilias e joses e tanias e elisetes e jonas e manoeis e luises e tadeus e luizes e janetes e neris e antonios e diones e gelsas e lourdes e adelaides e doras e vanildos e marias terezas e manueis e sergios e eudes e darios e romulos e nilzas e charles e vanias e ledos e marlenes e reginas e marias lauras e rafaeis e cristianos e rogeres e sonias e pitagoras e bigodes e rosas e denizaldes e carlos e gilles e filipes e euclides e felixes e marcosvinicius e clarisses e nilsons e marilias...

$$
\text { e... e... e... }
$$

\section{Referências ou coisas que nos afetam}

DELEUZE, Gilles. Nietzsche e a Filosofia. Porto: Rés Editora, 2001.

DELEUZE, Gilles; GUATTARI, Felix. Mil Platôs: capitalismos e esquizofrenia 2. vol. 1. São Paulo: Editora 34, 2014a.

DELEUZE, Gilles; GUATTARI, Felix. Mil Platôs: capitalismos e esquizofrenia 2. vol. 5. São Paulo: Editora 34, 2014b.

DELEUZE, Gilles; GUATTARI, Felix. O Anti-Édipo. São Paulo: Editora 34, 2014c.

FERNANDES, Filipe. S. A Quinta História: composições da Educação Matemática como área de pesquisa. 2014. 233 f. Tese (Doutorado em Educação Matemática) - Instituto de Geociências e Ciências Exatas, Universidade Estadual Paulista, Rio Claro, 2014.

LEITE, Marcos Vinícius. Trajetórias em devir(es) - como corpo se tornou quem. Como pensamento se tornou alguém e como algum se tornou língua ao vento, patas ao chão. 2014. 223 f. Exame Geral de Qualificação (Doutorado em Educação) - Faculdade de Educação, Universidade Federal de Juiz de Fora, Juiz de Fora, 2014.

LIMA, Marília; ALVARENGA, Nilson. O afeto em Deleuze: o regime cristalino e o processo afetivo da imagem-tempo no cinema. Esferas, Brasília, ano 1, no 1, julho a dezembro, 2012, p. 27-36.

LISPECTOR, Clarice. A quinta história. In: LISPECTOR, C. A legião estrangeira. Rio de Janeiro: Ed. do Autor, 1964, p.85-87.

PEREIRA, Denizalde. História do movimento democrático que criou a Sociedade Brasileira de Educação Matemática - SBEM. 2005. 261 f. Tese (Doutorado em Educação) - Faculdade de Educação, Universidade Estadual de Campinas, Campinas, 2005. 
VIANNA, Carlos. Filosofia da Educação Matemática. In: BICUDO, Maria. (Org.) Filosofia da Educação Matemática: concepções e movimentos. Brasília: Plano Editora, 2003, p. 45-57.

VIANNA, Carlos. Vidas e circunstâncias na Educação Matemática. 2000. 565 f. Tese (Doutorado em Educação) - Faculdade de Educação, Universidade de São Paulo, São Paulo, 2000.

Submetido em Abril de 2015. Aprovado em Julho de 2015. 